\title{
Ilya Shpuntou
}

(Uniwersytet im. Adama Mickiewicza w Poznaniu, Poznań - Polska)

\section{ВЫБРАННЫЕ АСПЕКТЫ АИНГВОКУАЬТУРОАОГИЧЕСКОГО АНААИЗА НАЗВАНИЙ КАРТОЧНЫХ ИГР РУССКОГО ЯЗЫКА}

Карточные игры (к.и.) всегда вызывали много дискуссий и споров. Для некоторых они были вымыслом дьявола, а для других стали целью жизни. К.и. давали возможность проиграть или выиграть целые состояния. И не важно даже, зависит ли наш выигрыш от удачи или от нашего мастерства, важны эмоции и надежды, которые появляются в момент игры. К.и. создали свой лексический мир, в котором существуют тысячи терминов, понятных только профессиональным игрокам и свойственных только карточным играм. Поэтому названия к.и. имеют особый характер.

В данной работе мы проанализировали этимологию названий карточных игр (н.к.и.) для того, чтобы узнать, какое было влияние иностранных языков на н.к.и. Далее мы рассмотрели изменения в н.к.и. на протяжении веков, и в конце нашей работы мы обратили внимание на связь между семантическим названием игры и ее формальными правилами.

Для данной работы мы собрали перечень н.к.и. состоящий из 318 единиц, а статистический метод был главным для нашей работы.

Большинство историков ${ }^{1}$ считает, что карты в России появились в XVII веке, проникнув, вероятно, через Польшу или Украину из Германии. По словам А.С. Афанасьева (Чужбинского) уже в начале XVIII века существовали такие игры, как трилистик, дурачки, свои козыри-мельник, короли, фофан, юрдон, марьяж, пикет, экарте, тентере, каламбриест, дружбарт, вист, бостон, гальбик, ландскнехт, банк, стос, квинтичь, мушка, кончинка, цхра, безик, ломбер, палки, преферанс, ералаш, рамс, стуколка, макао 2 .

Мы проверили этимологию этих названий, главным образом используя этимологический словарь Фасмера, а также ряд современных двуязычных переводных словарей․․ Таким образом, при подсче-

${ }^{1}$ В.Д. Казьмин, Лучшие карточные игры, Ростов-на-Дону 2006, с. 11.

2 В.В. Виноградов, Муху зашибить, муху задавить, муху раздавить, муху убить, с мухой, под мухой, [в:] его же, Русская речь, Москва 1968, с. 86.

${ }^{3}$ Если слово указывало на иностранное произношение напр. рокэуэй, хазенпфеффер, мы старались найти н.к.и. в оригинальном языке для того чтобы узнать его этимо- 
тах мы учитывали язык, который непосредственно влиял на н.к.и., а не язык, в котором слово появилось впервые.

Полученные результаты мы поместили в диаграмме 1. Согласно полученным данным, больше всего (10) французских названий, что дает 33\% целой группы (напр. пикет, экарте). Этимологически русские названия - на втором месте (6), и они составляют 20\% (напр. палки, дурачки). Немецких названий - 5, и это 17\% группы (напр. гальбик, дружбарт). Итальянских и португальских н.к.и - по 3\% (напр. банк и макао). Для 7 названий этимологию нам не удалось найти, что дает 23\% (напр. цхра, юрдон).

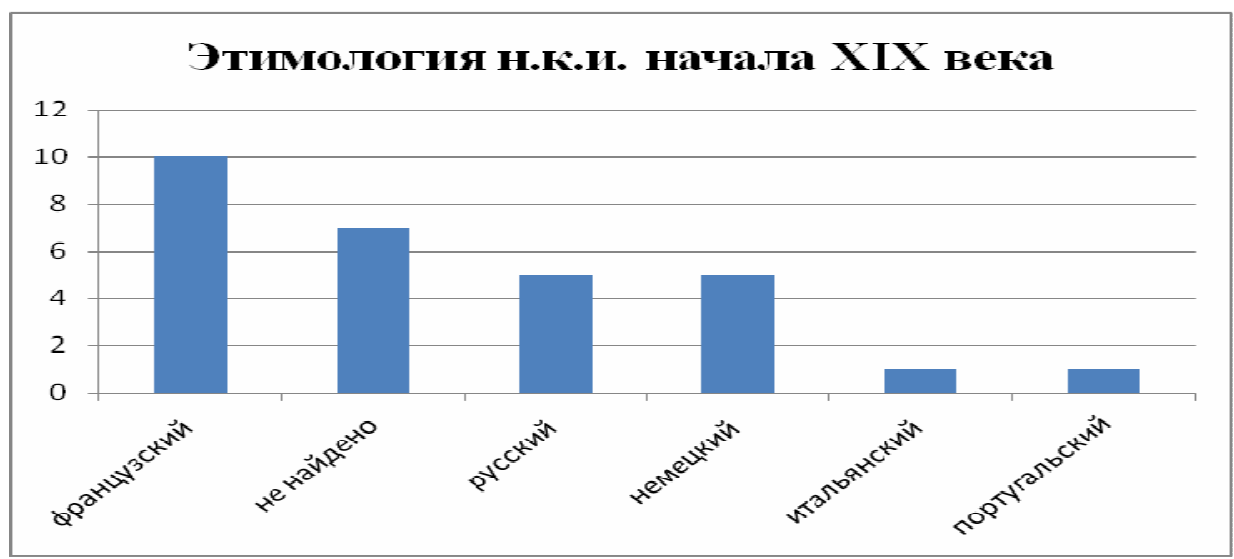

Диаграмма 1. Этимология н.к.и. начала XIX века

Такой же этимологический анализ мы провели со всеми собранными нами н.к.и., состоящими из одного слова (234). Результаты нашего анализа мы поместили в диаграмму 2. Мы видим, что этимологически русских слов - 97, что составляет $41 \%$ целой группы (напр. бочки, блин). Названий, для которых мы не нашли этимологию, 37 слов. Это 16\% общей группы. Далее 32 н.к.и., на которые имел влияние французский язык, они составляют около 13,5\% (напр. реверси, альянс). 30 названий английского происхождения - 13\% (напр. анандис, футбол). 15 названий, на которые повлиял немецкий язык, составляют 6\% (напр. хоггенхаймер, скат). 6 названий, на которые влиял латинский язык, составляют 2,5\% (напр. леопард, абракадабра). На 4 названия влиял итальянский язык они составляют 2\% (напр. банк, соло). На 2 названия повлияли испанский и португальский языки и они составили по 1\% (напр. канаста, макао). На 1 название повлияли: польский, греческий и датский языки и они составили по 0,5\% (напр. полицейский, элевзис, снип-снап-снуре).

логию. Итак, для данных примеров мы нашли их первоначальные названия: rockaway и hasenpfeffer. 


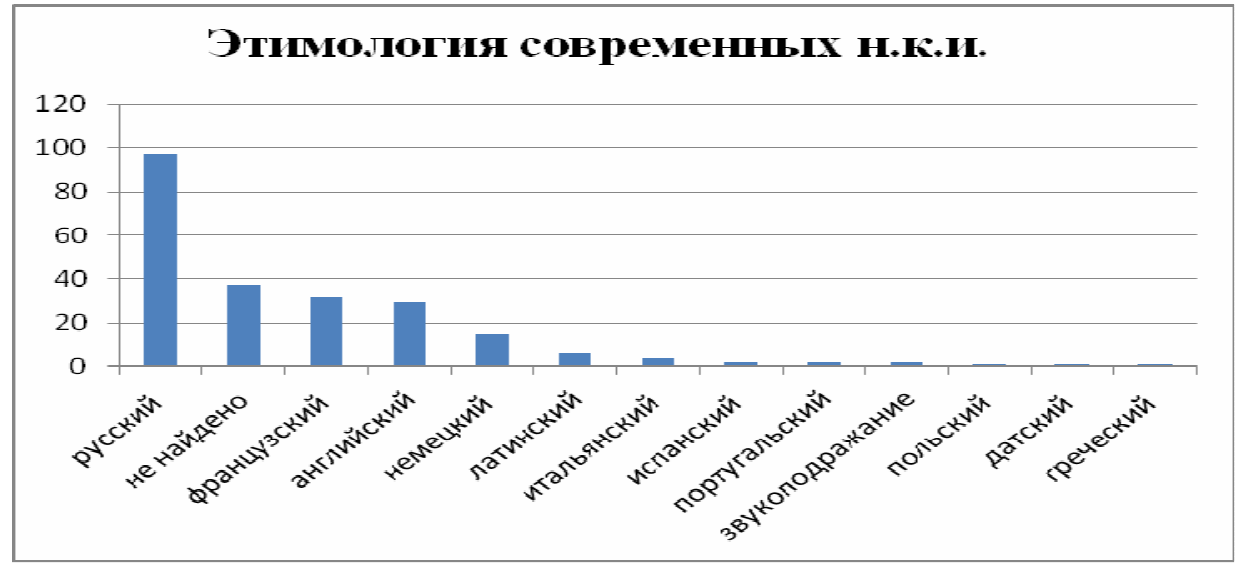

Диаграмма 2. Этимология современных н.к.и.

Сравнивая полученные данные, мы видим, что в начале XIX века не было ни одного английского названия, но преобладали французские и немецкие н.к.и. Связано это с тем, что большинство слов из французского и немецкого языков было заимствовано в периоде c XVIII по XIX век, а с английского с XX до начала XXI века. Следует обратить внимание на то, что русские н.к.и. впоследствии стали доминировать. Это непосредственно связанно с доступностью карт, которые стали самым популярным развлечением в простонародье, а позднее и пролетариате. В дальнейшем этот факт имел большое влияние на н.к.и., так как при создании н.К.и. использовались слова, характерные для народно-разговорного стиля (напр. бздун, дурак, пьяница, простак, жопа), названия зверей (напр. бабочка, белка, козёл, курица, осёл, петух), а также имена числительные (напр. одиннадцать, тринадцать, сто, тысяча).

На появление н.к.и. непосредственное влияние имели не только этимологические, словообразовательные, фонетические и другие факторы, но и формальные правила данной игры, поэтому мы проанализировали связь между семантической природой названия игры и ее правилами. Для этого мы создали классификацию из 7 групп.

Первой является группа, в которой находятся н.к.и., обозначающие понятия, использованные в правилах этой игры. Ярким примером этой группы является игра ази, в правилах которой присутствует термин, имеющий аналогичное название, обозначающее ситуацию, в которой ни один из игроков не имеет права принимать более одной так называемой „взятки"4.

4 Взятка - это ход каждого из игроков в одном круге. Игрок с самой старшей картой (либо имеющий самый старший козырь) считается обладателем взятки. 
В состав второй группы входят названия, указывающие на цель игры. Например, целью игры двадцать четыре является набрать менее 24 очков.

Третья группа включает в себя игры, названия которых указывают на их общие правила. Это прежде всего игра большая тройка, в которой 3 определенные карты считаются самыми старшими картами в игре.

К четвертой группе мы отнесли н.к.и., которые одновременно являются речевыми формулами. Примером такой к.и. является абракадабра, где игрок после того, как наберет заявленное количество взяток, должен произнести формулу - „абракадабра”. В противном случае действие игрока не засчитывается (ему не будут засчитаны очки).

В пятой группе нашлись н.к.и., которые каким-либо образом охарактеризовывают игру. Ярким примером является бридж, который в переводе с английского языка означает мост, что является метафорой соглашения между партнерами в определенных параметрах и стратегии игры.

В шестой группе присутствуют н.к.и., использующиеся для высмеивания проигравшего. Одной из таких игр является бздун, где игрока, занявшего последнее место, называют „бздуном“ или „бздуньей“", в зависимости от пола игрока. Н.к.и. в этом случае также является своего рода речевой формулой, являющейся обязательным элементом игры.

В седьмой группе - названия, которые семантически не связанны с игрой, напр. курица. Н.к.и. в данном случае - это случайное название, вошедшее в традицию употребления.

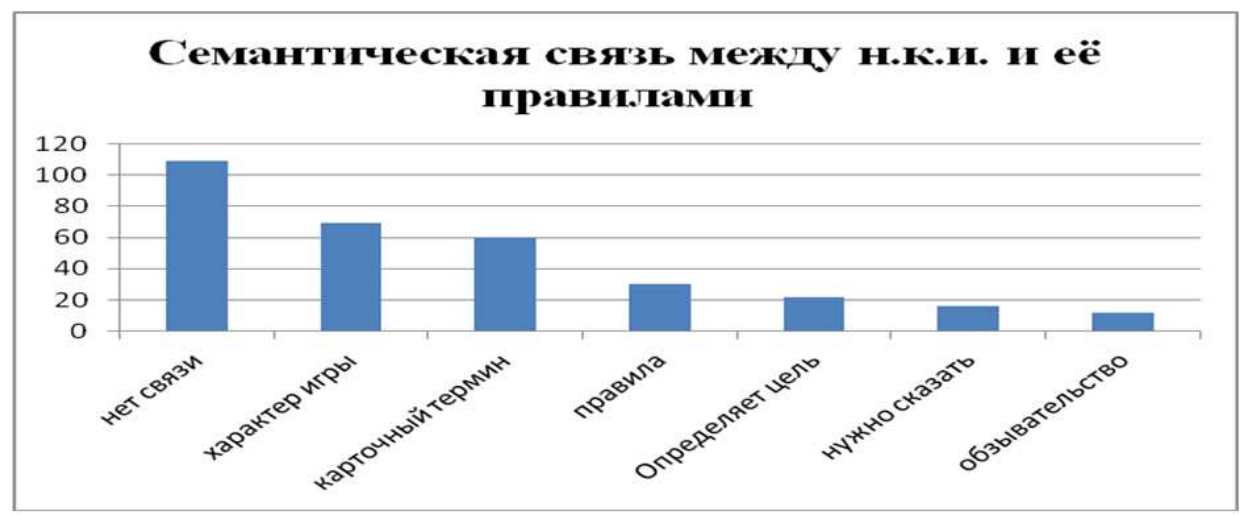

Диаграмма 3. Семантическая связь между н.к.и. и ее правилами

Согласно данным диаграммы 3, доминирующей группой (34\%) являются н.к.и., которые не связаны с игрой, ее функциями или па- 
раметрами. Остальные шесть н.к.И., в которых подтверждается связь с игрой, составляют 66\% н.к.и. В связи с этим, можно сделать вывод, что для образования н.К.и. чаще всего выбираются слова, которые в тот или иной способ охарактеризовывают ее.

Вторую по количеству группу составляют н.к.и., которые определяют характер данной игры. Они состявляют 21\% (напр. вслепую, карточная лотерея, копилка).

Следующей по количеству группой являются н.к.и., обозначающие понятия в данной игре (18\%). Такая многочисленность объясняется тем, что во многих играх выступают особые термины, свойственные только для одной конкретной игры, что является сильным фактором для образования названия (напр. ази, пок, рамс).

Названий игр, указывающих на ее правила, мы насчитали 9\% (напр. большая тройка, козырная семь, пики).

На цель игры указывает 6\% игр, при этом стоит отметить, что 13 из 16 имен числительных причислено именно к этой группе (напр. два, тринадцать).

Следующую группу составляет 5\% всех названий. Это н.к.и., которые надо произнести во время партии. Среди них можно выделить звукоподражания (бип-бип, бум), магические формулы (напр. абракадабра, снип-снап-снуре).

В самую малую группу, составляющую 4\%, входят н.к.и., которыми после игры называют игрока, чаще всего проигравшего (напр. бздун, говно, разгильдяй). Формально эти названия просторечны. Среди этой подгруппы только н.к.и. богач не имеет негативной окраски, так как, богачом называют игрока, который выиграл, а не проиграл.

Подводя итоги, мы хотим еще раз обратить внимание на два важных вывода. Во-первых, среди н.к.и. много иностранных слов, которые перешли в русский язык, главным образом, из французского, немецкого и английского языков во время их наиболее сильного влияния на русский язык, а в настоящее время появляется все больше русских н.к.и. Во-вторых, важным выводом является факт, что на появление и функционирование н.к.и. влияет не только языковые, но и экстралингвистические факторы, такие, как например, правила данной игры. 